\title{
Las economías
}

\section{Hubert Escaith \\ División de Desarrollo \\ Económico, \\ CEPAL \\ hescaith@eclac.cl}

La población, los recursos naturales y el tamaño del mercado interno han sido los componentes tradicionales de la ecuación que determina la riqueza de las naciones según los economistas clásicos. Los nuevos rumbos de investigación abiertos por las teorías del crecimiento endógeno y los resultados de estudios estadísticos comparativos sobre los factores determinantes de este crecimiento han reactivado el interés en las relaciones entre efectos de escala, tamaño de los mercados y papel del comercio internacional en el crecimiento económico de las economías pequeñas. En el contexto de una globalización cada vez mayor, estas economías se hallan confrontadas a una serie de desafíos y oportunidades en que su pequeña dimensión económica se considera generalmente una desventaja. Las deseconomías de escala aumentan sus costos de producción mientras que la menor diversificación de sus exportaciones las torna extremadamente vulnerables a las perturbaciones (shocks) de origen externo. Todos estos factores adquieren tanto más importancia cuanto que el comercio se ha convertido en uno de los factores claves del desarrollo económico, como lo indica el aumento notorio de la participación de las importaciones y exportaciones en el PIB a partir del segundo lustro de los años ochenta. La función central del comercio intrarregional o del mercado norteamericano como motores de las exportaciones no tradicionales exacerba la importancia de la competitividad-precio y, por ende, de los programas de subvenciones o exenciones para asegurar la salida a estos mercados. Para los pequeños países en desarrollo de la región que sufren desventajas relativas, el éxito dependería, por lo tanto, de las condiciones preferenciales de sus relaciones con sus principales socios comerciales desarrollados, es decir, América del Norte y, para los países en desarrollo de Africa, el Caribe y el Pacífico (grupo ACP), la Unión Europea. Por otra parte, una especialización excesiva en función de un gran mercado regional (Estados Unidos o Brasil) entraña riesgos que merecen considerarse. 


\section{Principales características económicas}

No existe una definición universalmente aceptada de lo que es una economía pequeña. Los análisis teóricos emplean a menudo como definición el hecho de tener o no tener influencia en la formación de los precios internacionales. Una caracterización similar, y más útil desde el punto de vista de la economía política, identifica a las economías pequeñas como aquéllas que carecen de autonomía para tomar decisiones de política económica y deben ajustarse al contexto creado por las políticas económicas de las grandes economías: ésta es en particular la que emplea De Sierra, coord. (1994). Definiciones de esta índole tienen poca utilidad para la investigación empírica, porque son difíciles de observar y medir. Por razones prácticas, generalmente el tamaño de una economía se mide en función de su población, superficie o ingreso interno (Damijan, 1997). Por su parte, Gutiérrez (1996) señala que en América Latina hay una fuerte correlación entre los diversos indicadores que suelen emplearse en la literatura y que una clasificación en términos de población permite ordenar, de manera simple pero claramente aceptable, las economías de la región.

Si se utiliza una definición de pequeña economía basada en la población (10 millones de habitantes o menos a comienzos de los años noventa), ${ }^{1}$ la mayoría de las economías de América Latina son pequeñas: todas las del Caribe (excepto Cuba), las del Istmo centroamericano, Bolivia, Ecuador, Paraguay y Uruguay. Muchas islas caribeñas tienen un tamaño muy reducido, menos de un millón de habitantes (a veces no llegan a cien mil personas), lo que acentúa su especificidad y las hace especialmente vulnerables (cuadro 1).

\footnotetext{
$\square$ El autor agradece a los participantes del coloquio internacional organizado en septiembre de 2000 por el Centre de Recherche sur l'Amérique Latine et les Caraibes (CREALC) en Aix-en-Provence, Francia, sobre las relaciones Europa-América Latina y la globalización, así como a los colegas de la CEPAL, en particular Len Ishmael, José Antonio Ocampo y Esteban Pérez, quienes enriquecieron con sus comentarios las versiones anteriores que sirvieron de base para elaborar este artículo. Las opiniones aquí vertidas son de la exclusiva responsabilidad del autor y pueden no coincidir con las de la CEPAL.

${ }^{1}$ Criterio muy relativo: 20 años antes, el límite habría sido de 6.1 millones para un grupo similar de países latinoamericanos (Real de Azúa, 1977); hoy es de 13 millones y Cuba se consideraría ahora una economía pequeña (cuadro 1).
}

No obstante, todas son muy diferentes en términos de recursos naturales, ingreso per cápita, cultura y sociedades, lo que obliga a poner en perspectiva las conclusiones generales que se formulan más adelante, a fin de evitar todo reduccionismo excesivo.

\section{Crecimiento y competitividad}

La literatura reciente sobre las economías de escala y el crecimiento endógeno de las economías abiertas tiende a considerar la estrechez del mercado interno como una desventaja, al menos en las etapas iniciales del desarrollo. La apertura de los mercados externos que permite la globalización debería en principio propender a que estas economías compensaran tal restricción. No obstante, no existe unanimidad sobre los resultados de la apertura comercial y el libre comercio cuando los socios comerciales son demasiado asimétricos en cuanto a tamaño y nivel de desarrollo. Tanto la teoría como la práctica tienden a indicar que ciertos países se desvían hacia vías lentas y se especializan en mercados regresivos, mientras que otros aprovechan los mercados externos para desarrollar una especialización dinámica (Ros, 2000).

Dentro del conjunto de países en desarrollo, las "economías grandes" ostentan un ingreso per cápita notoriamente más elevado que el de las "economías pequeñas"; en cambio, las "economías muy pequeñas" tienen un ingreso medio por habitante comparable al de las economías más grandes. Las mismas relaciones se obtienen cuando se examinan las tasas de crecimiento. Al parecer, las economías pequeñas (pero no las muy pequeñas) adolecen de ciertas desventajas comparativas (Salvatore, 1997). Según este autor, tales desventajas dependen del nivel de desarrollo y tienden a desaparecer cuando se analizan las economías desarrolladas. Estos resultados se repiten, si bien atenuados, en América Latina y el Caribe. En los veinte últimos años, las economías muy pequeñas (menos de un millón de habitantes en 1990) han tenido una tasa de crecimiento del ingreso por habitante al menos comparable, si no más elevado, que los países de tamaño mediano o grande (más de 10 millones de habitantes). Las pequeñas economías (entre 1 y 10 millones de habitantes) han registrado en general un crecimiento menor que los otros dos grupos. 


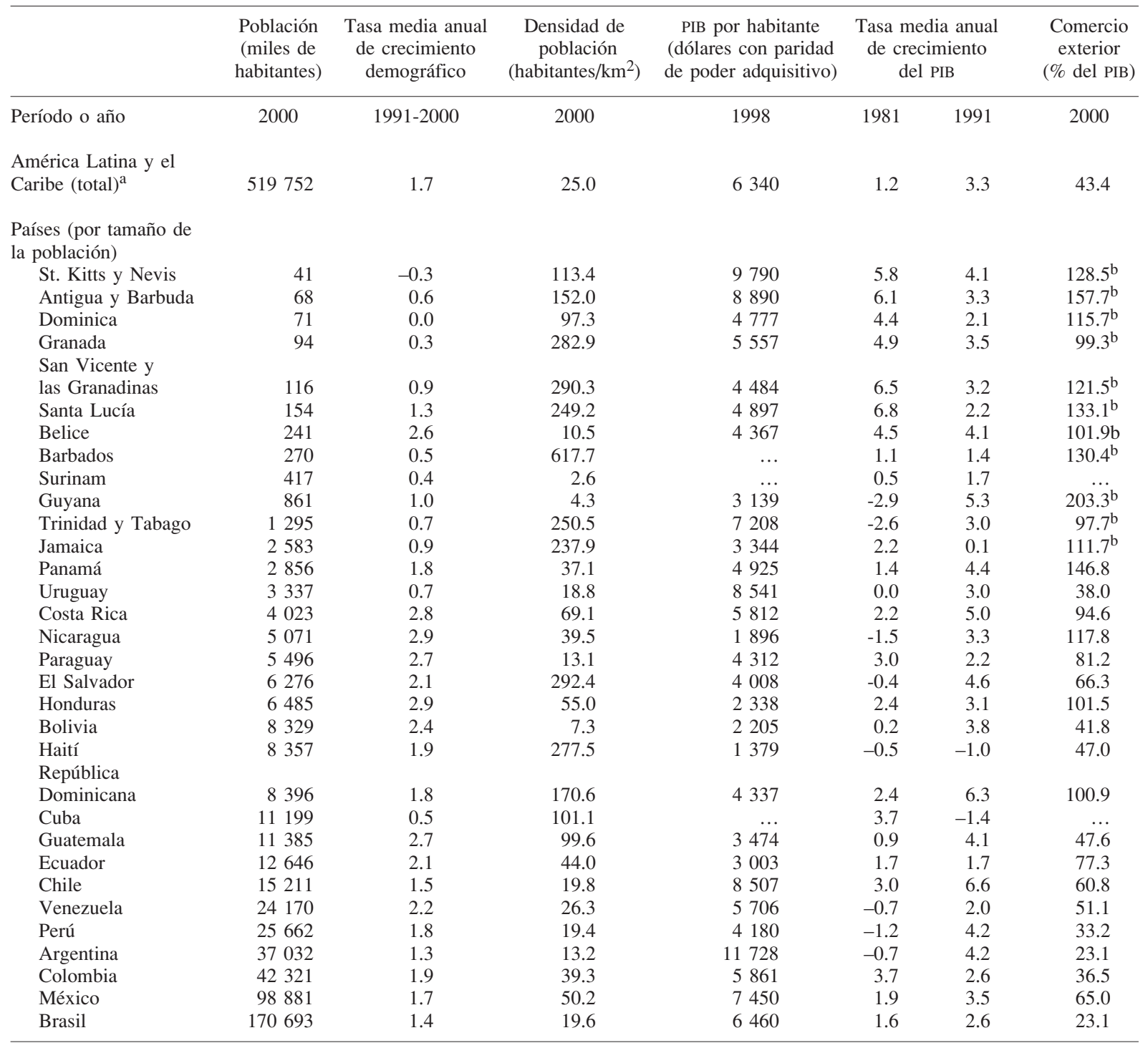

Fuente: CEPAL y Banco Mundial.

a Incluye Antillas Neerlandesas, Aruba, Bahamas, Islas Vírgenes, Montserrat y Puerto Rico.

b Sólo comercio de bienes, 1998.

De hecho, en un período prolongado, sólo las economías muy pequeñas registraron un aumento significativo del producto por habitante, mientras que en las medianas y grandes la recuperación del crecimiento en los años noventa fue apenas suficiente para compensar las pérdidas sufridas 10 años antes como consecuencia de la política de endeudamiento de los años setenta y de la crisis económica que la siguió (cuadro 2). En el grupo de 14 países pequeños, el ingreso medio per cápita en el año 2000 fue inferior al de 1980, de modo que para ellos la famosa década perdida habría durado veinte años. En ocho países de este grupo dicho indicador declinó en el período 1981-2000, lo que afectó particularmente a Haití y Nicaragua (2.6\% y $1.7 \%$ de caída media anual del PIB por habitante, respectivamente). El factor tamaño es sólo uno de muchos que pueden influir en la tasa de crecimiento y, por lo tanto, es necesario verificar la acción de esas otras 
CUADRO 2

América Latina y el Caribe: Evolución del ingreso y el tamaño económico, 1981-2000

\begin{tabular}{|c|c|c|c|c|}
\hline \multirow[t]{2}{*}{ Países } & \multirow{2}{*}{$\begin{array}{c}\text { PIB por } \\
\text { habitante, } 1990^{a}\end{array}$} & \multicolumn{3}{|c|}{ Tasa de crecimiento anual del PIB por habitante } \\
\hline & & $1981-1990$ & $1991-2000$ & $1981-2000$ \\
\hline Total $^{b}$ & $\ldots$ & -0.9 & 1.5 & 0.3 \\
\hline De América Latina ${ }^{b}$ & $\ldots$ & -0.9 & 1.5 & 0.3 \\
\hline Del Caribe ${ }^{b}$ & $\ldots$ & -0.9 & 1.0 & 0.0 \\
\hline Con más de 10 millones de habitantes ${ }^{\mathrm{c}}$ & 7029 & -0.5 & 1.5 & 0.5 \\
\hline Con 1 a 10 millones de habitantes ${ }^{\mathrm{c}}$ & 4056 & -1.2 & 1.1 & -0.1 \\
\hline Con menos de 1 millón de habitantes ${ }^{\mathrm{c}}$ & 6655 & 3.1 & 2.4 & 2.7 \\
\hline
\end{tabular}

Fuente: Cuadro 1.

a Dólares con paridad de poder adquisitivo.

b Promedio ponderado por el PIB.

c Promedio simple.

CUADRO 3

América Latina y el Caribe: Evaluación empírica de los determinantes del crecimiento

\begin{tabular}{lr}
\hline Variable & Coeficiente \\
\hline Constante & 3.237 \\
Población media en 1971-1975 (logaritmo) & 0.261 \\
Proporción de población rural, promedio 1971-1975 & -0.033 \\
Ingreso per cápita al comienzo de cada subperíodo de cinco años & -0.001 \\
Coeficiente de inversión (respecto al PIB) & 0.96 \\
Variación de las exportaciones de los países en desarrollo a la ocDE & -2.020 \\
Importancia de los sectores primarios en el PIB & -7.71 \\
Variación del coeficiente de exportaciones (respecto al PIB) & 1.94 \\
Participación de las reservas en divisas en M2 & 8.51 \\
Saldo presupuestario (respecto al PIB) & -0.125 \\
Fluctuaciones del tipo de cambio real & 0.127 \\
Variación de la proporción del crédito destinado al sector privado & 0.007 \\
Indice medio de reforma estructural, al comienzo de cada subperíodo & 0.154 \\
Cuadrado de este mismo índice medio, al comienzo de cada subperíodo & -0.097 \\
Variación del índice medio de reforma durante cada subperíodo & 0.037 \\
\hline
\end{tabular}

Fuente: Cálculos del autor. Origen y descripción de los datos: Escaith y Morley (2000).

a Variación anual del PIB per cápita.

b Método de los mínimos cuadrados ordinarios, ponderados y corregidos para tener en cuenta la heteroscedasticidad. R-2: 0.83 , con 85 observaciones (17 países, cinco subperíodos de cinco años entre 1971 y 1996).

causas posibles para aislar la contribución específica del tamaño del país. Con este fin, se estimó una ecuación que incorpora los diversos otros factores identificados por Escaith y Morley (2000) para un panel de 17 países de la región durante el período 1971-1996, que excluye a las economías muy pequeñas. Si bien se suscriben las advertencias de esos autores en cuanto a los límites de este tipo de análisis, los resultados (cuadro 3) tienden a indicar que, a igualdad de condiciones, ${ }^{2}$ los países grandes tuvieron una tasa de crecimiento del producto per cápita superior.
Las desviaciones observadas respecto a las predicciones de la teoría neoclásica, neutras en cuanto al efecto tamaño, se deben sobre todo a consideraciones microeconómicas. Con un mercado interno reducido hay ciertas economías de escala y complementarie-

\footnotetext{
${ }^{2}$ Entre los demás factores, la evolución del comercio internacional y la estabilidad del marco macroeconómico interno son los más determinantes. Las reformas estructurales no han tenido un efecto global significativo, pero la falta de progresividad en su aplicación ha tenido claramente un impacto negativo.
} 
dades que no pueden lograrse, lo que implica mayores costos relativos y una menor competitividad. Estos costos, que afectan tanto al sector público como al privado, adoptan diversas formas que pueden resumirse de la manera que se expone a continuación.

\section{a) Indivisibilidad, bienes públicos e infraestructura} La mayoría de los servicios públicos se caracteriza por su indivisibilidad, lo que implica para los países pequeños que su costo por habitante es generalmente elevado. Además, como veremos más adelante, la estructura incompleta o deficiente de los mercados obliga a menudo al Estado a asumir un papel importante en la economía. Por lo demás, la participación del gasto público corriente en el PIB y el coeficiente de tributación tienden a disminuir con el tamaño de las economías. La necesidad de mantener controlado el gasto del Estado implica también que la cobertura y calidad de estos servicios a menudo dejan que desear.

\section{b) Tamaño de las empresas y costos de producción} Las empresas privadas encaran los mismos problemas, ya que la estrechez del mercado interno impide aprovechar los rendimientos de escala. Esto es particularmente válido para el sector de bienes y servicios no transables, para el cual el mercado es por definición interno. Estas desventajas son menos acentuadas en el caso de los sectores de bienes y servicios transables, pues las exportaciones permiten compensar la estrechez del mercado interno. Sin embargo, incluso en este contexto de apertura es difícil lograr economías de escala, ya que incluso las "empresas grandes" de los países pequeños son chicas en comparación con sus competidoras regionales y, como muchas empresas pequeñas, tienen dificultades para seguir el ritmo del progreso tecnológico. Además, deben integrar en sus procesos productivos bienes y servicios no transables producidos localmente a precios que suelen ser muy superiores a los de sus competidores internacionales. En estas circunstancias, una inserción exitosa en los mercados regionales o internacionales pasa por una especialización suficiente para alcanzar una masa crítica. Esta especialización suele hacerse en detrimento de la complementariedad con el resto de la economía nacional.

\section{c) Estructura de los mercados}

La estrechez de los mercados y lo que esto implica en términos de competitividad tiene consecuencias importantes para la organización de los mercados in- ternos. La existencia de empresas viables en los sectores expuestos a la competencia externa es más reducida, debido a los altos costos unitarios de producción. En los sectores protegidos tiende a predominar una estructura monopolística poco cuestionada dado que los costos iniciales para acceder a esos mercados pequeños son relativamente importantes comparados con los ingresos previsibles.

Esta tendencia monopolística de los mercados internos exige una intervención pública - sea espontánea, sea forzada del exterior por los acuerdos comerciales multilaterales - para corregir las fallas del mercado y regular la competencia. Ahora bien, por razones financieras y falta de especialistas, la entidad pública local rara vez es capaz de asumir las complejas implicaciones legales y técnicas de una regulación de esta especie. Las consecuencias en términos de menor eficiencia de los mercados crean entonces una situación subóptima desde un punto de vista económico.

Tanto la estrechez del mercado laboral como la menor diversificación de las actividades productivas acarrean costos importantes de fricción y ajuste. En períodos de crecimiento, las empresas tienen dificultades para contratar la mano de obra calificada necesaria. En cambio, en situaciones recesivas, las alternativas de empleo son reducidas dado que las actividades son poco diversificadas. El desempleo inducido se reabsorbe con dificultad y las perturbaciones tienden a ser persistentes. ${ }^{3}$ Este último aspecto tiene especial importancia cuando se consideran los costos sociales de una eventual reestructuración productiva que impondría una apertura al libre comercio.

\section{d) Gobernabilidad}

El tamaño reducido de los mercados, por otra parte, ofrece ventajas vinculadas con las deseconomías de escala en términos de costos de transacción y supervisión. En un contexto en que la información sobre los socios comerciales (clientes, proveedores) es de fácil acceso, los costos asociados a la asimetría de información y al riesgo moral disminuyen. La reputación y la presión del medio para comportarse según las normas éticas convenidas sustituyen en parte la necesidad de implantar un sistema formal de regulación y vigilancia. El menor tamaño de la población obra asimismo a favor de una mayor cohesión social y una mayor

\footnotetext{
${ }^{3}$ Las economías pequeñas se caracterizan además por una fuerte emigración de su mano de obra.
} 
participación de los ciudadanos en la gestión de la cosa pública. ${ }^{4}$ No obstante, estas ventajas sólo serán fructíferas si se reúne un mínimo de condiciones de gobernabilidad, lo que está lejos de ocurrir en la región. ${ }^{5}$

\section{Vulnerabilidad}

Más allá de las diferencias de nivel de desarrollo o crecimiento, las economías pequeñas como grupo son intrínsecamente más vulnerables a las perturbaciones externas. De hecho, la vulnerabilidad es una de las dimensiones principales del análisis de las relaciones entre tamaño y bienestar económicos en el contexto de las economías abiertas, a tal punto que muchos países pequeños han tratado — sin éxito hasta ahora- de introducir esta noción como criterio alternativo de diferenciación en la cláusula de habilitación que amplía el trato reservado a los países menos adelantados en los acuerdos de la OMC. Cabe distinguir tres factores interdependientes que responden a las dimensiones geográfica, demográfica y económica.

La conjunción de las dimensiones geográfica y demográfica se traduce en mayores densidades de población que incrementan la presión sobre los recursos naturales, amenazando el frágil ecosistema. Haití es el ejemplo más extremo, pero la vulnerabilidad ecológica está presente en muchas economías pequeñas de la región, cuya localización en regiones tropicales sujetas a desastres naturales (huracanes, fenómenos sísmicos o volcánicos) complica aun más el problema. Estos desastres naturales son recurrentes y cada episodio afecta a un gran porcentaje de la población y puede llegar incluso a incluir la totalidad del territorio. En ciertas islas del Caribe, los daños infligidos a la infraestructura y la actividad productiva pueden sobrepasar el valor del PIB. En esta situación, la capacidad de las autoridades nacionales para encarar la urgencia de la situación y asumir los costos de la reconstrucción es irrisoria.

En cuanto al aspecto específico de la vulnerabilidad social, se debe prestar especial atención a las pequeñas islas en desarrollo del Caribe, utilizadas a veces como puntos de tránsito o de lavado de dinero por los traficantes internacionales de drogas. La crimina-

\footnotetext{
4 Ya Aristóteles mencionaba esta cohesión como una fuerza de los Estados, noción retomada en reiteradas ocasiones por los autores del siglo XVIII (Real de Azúa, 1977).

${ }^{5}$ Como atestiguan las guerras civiles que han asolado Centroamérica, los conflictos étnicos y religiosos en el Caribe y las fracturas de la sociedad ecuatoriana.
}

lidad interna vinculada al comercio y el consumo de estupefacientes socava los sistemas judicial y financiero, y corrompe por último el conjunto de las instituciones involucradas en la gobernabilidad. La fragilidad social de estas islas y sus efectos en la gobernabilidad se agudizan todavía más debido a las fracturas sociales y culturales arraigadas en sociedades donde existe una distribución desigual del ingreso y brechas difíciles de reducir basadas en la etnia o la religión.

La dimensión económica de la vulnerabilidad de las pequeñas economías está estrechamente ligada a la importancia relativa del comercio internacional y a la escasa diversificación de sus exportaciones. El coeficiente de apertura comercial (importaciones más exportaciones de bienes y servicios) de las economías pequeñas de América Latina y el Caribe llega al 85\% del PIB, comparado con sólo 30\% en las demás economías de la región (CEPAL, 1996). Además, estas exportaciones se concentran en un pequeño grupo de productos y mercados, lo que hace muy volátil el ingreso de divisas provenientes de las ventas externas. Dado que el coeficiente de apertura es muy elevado y que estas economías pequeñas son extremadamente dependientes de las importaciones para satisfacer el grueso de su demanda interna, las fluctuaciones del ingreso de exportación -en general insuficiente incluso en períodos normales para financiar las importaciones- tienen un impacto significativo sobre la actividad interna y la generación del ingreso interno.

La naturaleza preferencial del acceso de los productos de exportación a los mercados europeo y estadounidense (acuerdos de Lomé, Iniciativa de la Cuenca del Caribe) los torna además dependientes de la continuidad de las preferencias unilaterales acordadas. Ahora bien, el espíritu mismo de estas preferencias se ve cada vez más cuestionado por las nuevas reglas que rigen el comercio internacional desde el término de la Ronda Uruguay.

La especialización en productos sensibles, como los agrícolas, textiles y vestuario, hace que los mercados de exportación sean vulnerables a las reacciones proteccionistas de las economías desarrolladas. Además, las manufacturas exportadas por los países de Centroamérica y el Caribe (provenientes de maquiladoras) tienen poca densidad de capital, lo que permite que las empresas de subcontratación se trasladen fácilmente y sean muy sensibles a pequeñas variaciones de los costos comparativos de producción.

Sin embargo, esta gran vulnerabilidad a las perturbaciones externas de origen comercial se compensa con una relativa inmunidad a aquéllas de origen 
financiero, que han sido la causa principal de las últimas crisis económicas en América Latina. Gracias al escaso desarrollo de sus mercados financieros, las economías pequeñas no han atraído el interés de los capitales especulativos, que por la amplitud de sus flujos y su volatilidad han sido la causa de grandes variaciones tanto de los precios relativos - mediante las desviaciones del tipo de cambio real- como de la transferencia de ingresos.

Nótese que la gran vulnerabilidad externa, de origen comercial, inherente a las economías pequeñas de la región, las ha llevado a adoptar políticas macroeconómicas generalmente más prudentes que las de sus vecinos. Gracias a este conservadurismo relativo y a su aislamiento de los movimientos especulativos de capitales, durante los veinte últimos años las fluctuaciones observadas del crecimiento de las pequeñas economías de la región son en general inferiores a las registradas en los países de mayor tamaño. Este resultado confirma también que la coherencia y calidad de la política macroeconómica han contribuido de manera importante a los resultados del crecimiento a largo plazo, observado en el conjunto de la región durante los treinta últimos años (Escaith y Morley, 2000).

\section{Políticas económicas}

Tanto su tamaño como su apertura al exterior imprimen un carácter distintivo a las políticas económicas seguidas por las economías pequeñas de la región. Más que a una opción voluntaria, este carácter responde a los escasos márgenes de maniobra que se asocian a mercados internos incompletos y a una apertura al exterior que incluye no sólo el comercio, sino también los mercados cambiarios. La estrechez de los mercados financieros locales y la precariedad del ahorro interno refuerzan el "trilema" clásico de las economías abiertas, en que el libre comercio, la estabilidad del tipo de cambio y la autonomía de la política monetaria son objetivos globalmente incompatibles. En estas condiciones, es muy difícil que frente a una perturbación recesiva las autoridades nacionales atenúen la demanda interna mediante una expansión del financiamiento interno, sin correr el riesgo de desestabilizar la economía. $^{6}$

\footnotetext{
${ }^{6}$ No obstante, esta menor capacidad de reacción de la política macroeconómica frente a las perturbaciones externas no se traduce en una mayor fluctuación de las tasas crecimiento, gracias por cierto al aislamiento de las pequeñas economías de los flujos de capitales especulativos.
}

La estabilidad del tipo de cambio es uno de los objetivos primordiales en estas pequeñas economías tan abiertas al comercio internacional, y en ellas las fluctuaciones del tipo de cambio real son menores que en sus vecinos de mayor tamaño. Durante el período 1989-2000, la desviación típica de los índices del tipo de cambio (normalizados a un valor 100 para 1995) fue de 11 para las economías pequeñas, comparada con 21 para los demás países. La mayoría de las economías pequeñas ha mantenido un tipo de cambio fijo mucho después del término del patrón dólar definido en Bretton Woods. Si bien entre los países centroamericanos Costa Rica fue el primero en devaluar (diciembre de 1980), éste fue un caso aislado y las paridades fijas siguieron siendo la norma durante los años ochenta, a expensas de una multiplicidad de tipos de cambio, restricciones no arancelarias a las importaciones y la acumulación de desequilibrios crecientes de la balanza de pagos. En el Caribe, las principales economías (Jamaica, Guyana, Trinidad y Tabago, República Dominicana, Haití) trataron también de mantener su paridad cambiaria a pesar de alarmantes desequilibrios internos y externos, que finalmente provocaron devaluaciones sobre la marcha y la aplicación de programas de ajuste.

Sin embargo, las economías más pequeñas del Caribe han logrado conservar una paridad estable (primero con la libra, luego con el dólar), dentro del marco de un régimen normal de tipo de cambio fijo (Barbados, Bahamas, Belice), o de un sistema monetario de conversión administrado por el Banco Central del Caribe Oriental, que reúne a seis países. Esta estrategia sólo ha sido posible gracias al conservadurismo de la política macroeconómica y de las transferencias de recursos, sea directas (ayuda al desarrollo), sea mediante el sesgo de los acuerdos comerciales preferenciales (protocolos específicos de los acuerdos de Lomé con la Comunidad Europea). En América del Sur, por razones geográficas e históricas, la política macroeconómica de las pequeñas economías durante los años ochenta se mantuvo cercana a la seguida por sus vecinos de mayor tamaño. En general, ahí también se practicó el anclaje del tipo de cambio en los esfuerzos de estabilización de los años noventa.

La política fiscal es asimismo poco autónoma, debido a la fragilidad de las finanzas públicas y su dependencia externa. Por un lado, los países pequeños tienen en general un déficit presupuestario más elevado que sus vecinos de mayor tamaño. Por otro, el ingreso corriente del gobierno proviene en gran parte del 
comercio exterior. A ello cabe agregar que en los países pequeños de menor desarrollo relativo, la inversión pública se basa en una ayuda externa proporcionalmente más elevada en relación al contexto regional.

En el cuadro 4 se observa que los países más vulnerables a las fluctuaciones económicas, según la doble clasificación de déficit fiscal y dependencia externa, corresponden casi todos a economías pequeñas. Así, en éstas la política macroeconómica sigue siendo muy reactiva, y más que en otros lugares apunta a controlar la inflación y preservar la estabilidad nominal del tipo de cambio, dos objetivos muy interdependientes en esta clase de economías. Por lo demás, los hechos demuestran que las economías pequeñas tienen menos problemas de inflación o devaluación que sus socios regionales de mayor tamaño (CEPAL, 1996).

No obstante, estas limitaciones estructurales a la utilización activa y autónoma de la política macroeco- nómica de corto plazo no implican renunciar a una política de desarrollo. Así, las restricciones fiscales no han impedido que ciertas economías pequeñas —en particular Costa Rica y las del Caribe anglohablanteestablezcan programas de inversión en capital humano (salud y educación) o apliquen los instrumentos fiscales de una política agresiva de exportación.

Como no pueden financiar costosos programas de ayuda al desarrollo industrial, muchas economías pequeñas han acordado subvenciones a la inversión productiva en forma de exención de impuestos, tanto directos como indirectos. Esto ocurre en particular en el caso de las actividades de maquila que se han instalado en las zonas francas, tanto en Centroamérica como en el Caribe. Algunos países han coparticipado en el desarrollo de la infraestructura necesaria para las nuevas actividades, como fue el caso en la República Dominicana dentro del marco de su programa de fomento del turismo. Estas acciones representan costos

CUADRO 4

América Latina y el Caribe: Situación presupuestaria

y dependencia de los ingresos aduaneros

(Promedios 1995-1999)

\begin{tabular}{|c|c|c|c|}
\hline $\begin{array}{l}\text { Saldo } \\
\text { presupuestario } \\
\begin{array}{l}\text { Dependencia de los } \\
\text { ingresos aduaneros: }\end{array}\end{array}$ & $\begin{array}{l}\text { Superávit o } \\
\text { leve déficit }\end{array}$ & Déficit moderado ${ }^{\mathrm{b}}$ & Déficit importante ${ }^{\mathrm{c}}$ \\
\hline Reducida & Trinidad y Tabago & $\begin{array}{l}\text { El Salvador } \\
\text { México }\end{array}$ & $\begin{array}{l}\text { Bolivia } \\
\text { Brasil } \\
\text { Costa Rica } \\
\text { Uruguay }\end{array}$ \\
\hline Moderada & Chile & $\begin{array}{l}\text { Argentina } \\
\text { Barbados } \\
\text { Guatemala } \\
\text { Panamá } \\
\text { Paraguay } \\
\text { Perú }\end{array}$ & $\begin{array}{l}\text { Ecuador } \\
\text { Guyana }\end{array}$ \\
\hline Alta & República Dominicana & $\begin{array}{l}\text { Antillas Neerlandesas } \\
\text { St. Kitts y Nevis } \\
\text { Santa Lucía } \\
\text { San Vicente y las Granadinas } \\
\text { Venezuela }\end{array}$ & $\begin{array}{l}\text { Antigua y Barbuda } \\
\text { Bahamas } \\
\text { Belice } \\
\text { Colombia } \\
\text { Dominica } \\
\text { Granada } \\
\text { Haití } \\
\text { Honduras } \\
\text { Nicaragua } \\
\text { Jamaica }\end{array}$ \\
\hline
\end{tabular}

Fuente: Escaith e Inoue (2001).

a Excedente presupuestario o déficit inferior a $1 \%$ del PIB.

b Déficit comprendido entre $1 \%$ y $2 \%$ del PIB.

c Déficit medio superior a $2 \%$ o altamente inestable. 
importantes, en términos de gasto presupuestario o impuestos no percibidos. ${ }^{7}$

Sin embargo, estos programas de incentivos son a menudo necesarios para contrapesar las deficiencias estructurales (deseconomías de escala, costos de externalidades) propias de las pequeñas economías, que como hemos visto aumentan los costos de producción y menoscaban la competitividad internacional de las producciones locales. El hecho es que ellos fueron muy a menudo la clave del éxito de los programas de diversificación de exportaciones no tradicionales de las economías pequeñas de Centroamérica y el Caribe (Stallings y Peres, 2000).
Las nuevas condiciones del mercado internacional, en particular las normas definidas dentro del marco de la Ronda Uruguay y los acuerdos internacionales y multilaterales que emanaron de ella, tienen particular importancia para estas economías, en las cuales la estabilidad de las finanzas públicas depende de aranceles aduaneros en vías de reducción y la inserción en la economía internacional depende de subsidios a la exportación cuyo uso disminuye cada vez más. La calidad de esta inserción y las condiciones en que opera presentan desafíos, pero también oportunidades, que condicionan en buena parte la definición de las opciones de política económica.

\section{II}

\section{Desafíos y oportunidades}

\section{Globalización, libre comercio e integración regional}

Según la ortodoxia económica, se supone que las economías pequeñas son las principales beneficiarias del libre comercio: los partidarios de la globalización sostienen que las desventajas derivadas del tamaño pueden ser reabsorbidas por la integración regional y la internacionalización de las actividades productivas. La apertura de los mercados permite superar estas desventajas ya que los países pequeños, gracias a una menor inercia estructural, estarían en mejores condiciones de mostrar la flexibilidad necesaria para adaptarse a las condiciones de la competencia internacional, en la medida en que sus gobiernos adopten las políticas "adecuadas". Lamentablemente, estas perspectivas optimistas son muy inciertas, y una ojeada a la literatura teórica sobre el impacto del libre comercio en el bienestar económico no permite determinar un consenso sobre sus consecuencias para las pequeñas economías (Escaith y Pérez, 1999). Rodríguez y Rodrik (1999), tras hacer una lectura crítica de los trabajos empíricos publicados sobre el tema, concluyen que sus resultados no son más convincentes.

Dicho en forma más concreta, muchos dirigentes de las pequeñas economías han formulado reservas

\footnotetext{
${ }^{7}$ Por ejemplo, en la República Dominicana los fondos de apoyo al desarrollo de la infraestructura hotelera ascendieron a 1.1\% del PIB en 1986, mientras que los ingresos no percibidos por concepto de impuestos exentos oscilaron, según los años, entre 5\% y $9 \%$ del ingreso fiscal en Costa Rica (Escaith e Inoue, 2001).
}

sobre la capacidad de sus países para beneficiarse plenamente de la iniciativa de crear una gran Área de Libre Comercio de las Américas (ALCA), como corolario del proceso iniciado en la primera Cumbre de las Américas realizada en 1994 para fomentar la integración comercial del conjunto de economías del continente. Las limitaciones estructurales que confrontan las pequeñas economías reducen, según ellas, los beneficios potenciales que podrían alcanzar sus (pequeñas) empresas con la ampliación de los mercados de exportación, mientras que el aumento de la competencia de grandes empresas externas las hace temer por su supervivencia.

Estas dudas no deben ocultar los beneficios netos que pueden aportar los nuevos flujos de comercio e inversión, en particular si se toman en cuenta los costos de oportunidad de la no integración. De hecho, las pequeñas economías de Centroamérica y el Caribe no tienen muchas opciones alternativas a la de integrar el ALCA, entidad que debería resultar de la suscripción (prevista para 2005) de este acuerdo de libre comercio: si rehúsan someterse a las reglas del libre comercio, correrían el riesgo de aislarse de los mercados que hoy constituyen la parte más importante y más dinámica de sus exportaciones. Si bien estos países se benefician hoy de un trato aproximado - aunque todavía con muchas restricciones- al de México en sus exportaciones a los Estados Unidos, excluirse del ALCA implicaría que estos privilegios, acordados unilateralmente, podrían ser revocados también unilateralmente. La mera existencia de esta posibilidad reduciría las 
ventajas que pudieran obtener de la liberalización del comercio, y, sobre todo, de los movimientos de inversiones.

\section{Costos y beneficios previstos}

Desde el punto de vista de una economía pequeña, al sopesar los costos y beneficios potenciales se deberían considerar los aspectos que se enumeran a continuación.

\section{a) Creación versus desviación del comercio}

El caso es clásico y se refiere a la existencia de barreras arancelarias que desvían los flujos de comercio existentes a favor de otro miembro de la zona de libre comercio y en detrimento de socios externos inicialmente más competitivos. En tal contexto, y considerando el conjunto de los costos de transacción, la formación de una zona de libre comercio entre socios comparables debería en teoría ser beneficiosa, siempre y cuando esta zona siguiera las líneas dictadas naturalmente por la proximidad (bloques naturales). Esta proximidad de hecho permite minimizar los efectos de desviación. Los bloques contra natura (es decir, que engloban a socios improbables o separados por grandes costos de transacción) son menos susceptibles de contribuir al mejoramiento del bienestar económico de las poblaciones (Frankel, Stein y Wei, 1995). Este último aspecto es potencialmente preocupante para pequeñas economías con costos elevados de transacción, sea por su insularidad (el caso del Caribe) o, al contrario, por su mediterraneidad (Bolivia y Paraguay). Este esquema se torna - por lo menos bajo ciertas hipótesis teóricas- aun más sombrío para estas economías pequeñas cuando se toma en cuenta la asimetría entre los socios comerciales. Dentro de un referente teórico de competencia imperfecta, los beneficios obtenidos de la adhesión a una zona de libre comercio estarían vinculados en último término al tamaño relativo de los socios: los países grandes se ven en general favorecidos en detrimento de las economías pequeñas.

No obstante, como ya se ha sugerido, las pequeñas economías realmente no tienen opción: la amenaza de una desviación del comercio es un costo para todo tercer país que puede asistir al colapso de su participación en el mercado si se mantiene fuera de una zona de libre comercio. ${ }^{8}$

\footnotetext{
${ }^{8}$ La situación empero no es tan clara cuando se considera el conjunto de las relaciones comerciales. En el caso del Caribe en parti-
}

\section{b) Asociación e inversión}

Integrar una zona de libre comercio no sólo permite al país ampliar sus mercados (creación de comercio), sino también reducir la incertidumbre sobre el acceso a esos mercados. Esta mayor seguridad debería traducirse a su vez en un gran estímulo de las inversiones destinadas a producir bienes y servicios exportables. No obstante, este beneficio previsto es también un presente griego, cuando las inversiones son muy específicas de los mercados elegidos e implican montos iniciales importantes o no recuperables. Como veremos más adelante, esta situación implica a la larga una pérdida de poder de negociación no carente de costos.

\section{c) Externalidades positivas}

Las autoridades macroeconómicas de un país que tiene un pasado de inestabilidad pueden ganar credibilidad y reducir la percepción de riesgo-país uniéndose a socios más estables. Por el contrario, a causa del efecto de contagio, la entrada de muchos socios inestables puede representar un costo para los "buenos alumnos"; por eso suele exigirse un certificado de buena conducta macroeconómica como requisito para integrar una zona de esta índole.

Otros efectos inducidos son previsibles, como la consolidación del proceso de reformas internas o la convergencia más rápida hacia normas de calidad reconocidas internacionalmente, lo que debería permitir la apertura de nuevos mercados fuera del ALCA (Europa, Japón). En la misma línea de razonamiento, la obligación de satisfacer criterios más estrictos de protección del medio ambiente debería llevar a abrir nuevos mercados, beneficiando también a las poblaciones locales. Estas externalidades pueden ser importantes para ciertos países, cuando la adhesión al ALCA permita ayudar a consolidar la adhesión de la comunidad nacional a la ejecución de programas de ajuste estructural y de reinserción sostenible en la economía mundial (Finger, Ng y Soloaga, 1998).

Dicho en forma más concreta, la pertenencia a una gran zona de libre comercio abre nuevas posibilidades de asociarse con países vecinos para realizar juntos grandes proyectos, sobre todo para la producción de servicios públicos especializados o particularmente

cular, que tiene un alto porcentaje de comercio con Europa, integrarse al ALCA podría traducirse en un gran efecto de desviación en contra de Europa y en una especialización excesiva en relación con los Estados Unidos. Sería entonces preferible que mantuviera un cierto equilibrio entre sus dos grandes socios comerciales. 
costosos (como educación superior y formación profesional, infraestructura, regulación de mercados y otros).

\section{d) Dependencia}

El balance de costos y beneficios se vuelve todavía más complicado cuando se toma en cuenta la economía política y la relación de fuerzas. ${ }^{9}$ Un primer elemento es la capacidad de cada país de manipular para su provecho las condiciones del intercambio mediante modificaciones unilaterales de los aranceles o la instauración de restricciones no arancelarias, en el caso de que estalle una guerra comercial en el seno de la zona de libre comercio. Como esta capacidad depende mucho de los tamaños respectivos, para una economía grande los beneficios potenciales de un conflicto abierto con un economía pequeña pueden sobrepasar con creces los costos inmediatos. Desde un punto de vista dinámico, las cosas se complican aun más para la economía pequeña, pues su grado de especialización en función de las relaciones comerciales con su socio mayor va a ser relativamente más elevado. Una vez que la especialización se torna irreversible, su poder de negociación puede reducirse a la nada (McLaren, 1997). Una figura teórica de este especie puede ser singularmente pertinente para caracterizar los fenómenos de industrialización basados en las actividades de subcontratación, como las que pueden observarse en ciertos países del Caribe y Centroamérica.

Sin embargo, los mismos modelos teóricos sugieren que, mientras la irreversibilidad no sea completa, la especialización no es una desventaja redhibitoria si el país grande atribuye un peso suficiente a los beneficios previstos del libre comercio (Park, 2000). Este aspecto teórico puede tener implicaciones interesantes para el país pequeño en términos de estrategia de negociación y alianza.

\section{e) Efectos del desfase entre costos y beneficios}

Desde una perspectiva teórica y práctica, generalmente se reconoce que los beneficios eventuales del libre comercio son difusos y de largo plazo, mientras que los costos son visibles en el corto plazo y afectan a algunos grupos bien específicos. Este último aspecto puede obrar, en particular, contra la adhesión a una zona de libre comercio (aunque, como ya se señaló, una vez creada la zona los exportadores de terceros países tienden a presionar por una adhesión de sus países a

\footnotetext{
${ }^{9}$ Para un análisis del proceso de integración regional en estos términos, véase en particular Dabène (1998).
}

fin de limitar los efectos de desviación). Desde otra perspectiva, la distribución asimétrica de costos y beneficios en el tiempo puede ser un factor crítico si se considera la gran vulnerabilidad de las pequeñas economías a las perturbacioness externas. En casos extremos, si la adhesión no se hace en forma gradual y si las perturbaciones se acumulan en los primeros años, la economía pequeña puede entrar en crisis y verse obligada a salir del acuerdo. De ahí la importancia de considerar explícitamente la vulnerabilidad cuando se estudia el grado de preparación de las economías para incorporarse a una zona de libre comercio.

\section{Grados de preparación}

La resultante de los costos y beneficios de la integración ya mencionados dependerá en gran parte del grado de preparación de estas economías para integrar una zona de libre comercio. Medir esa preparación es una manera de evaluar ex ante la capacidad de una economía dada de minimizar los costos y maximizar los beneficios. Uno de los primeros trabajos publicados en este sentido fue el de Hufbauer y Schott (1994). Una de las evaluaciones más completas de este grado de preparación (CEPAL, 1996) fue realizada como apresto a las negociaciones del ALCA y desarrollada en Escaith y Pérez (1999). La metodología de la CEPAL considera 55 indicadores, agrupados en cuatro categorías: elegibilidad, variables fundamentales, políticas y riesgos, subdivididas a su vez según su naturaleza (macroeconómica, comercial, etc.).

El estudio de estos indicadores confirma en general los análisis teóricos ya presentados. Las pequeñas economías no se diferencian de manera significativa de los países grandes en cuanto a su grado global de elegibilidad, pues sus dificultades fiscales y de balanza de pagos se ven compensadas por una mayor estabilidad monetaria y cambiaria. Su situación empeora, no obstante, si se consideran criterios no macroeconómicos, debido a los rezagos acumulados en la aplicación de las normas internacionales del derecho laboral o la protección del medio ambiente.

Como hemos visto, los países del Caribe y Centroamérica van a la zaga en sus reformas fiscales y siguen muy dependientes de los ingresos aduaneros. Estos aranceles generalmente son incluso más elevados y más dispersos que los de sus vecinos grandes, lo que implica una cierta propensión al proteccionismo. Asimismo, los indicadores fundamentales muestran en general un rezago de las economías pequeñas y exigen por ende un esfuerzo más sostenido de las políticas de ayuda a la reconversión y al desarrollo industrial. 
Este rezago se explica a menudo por su nivel de desarrollo relativo o por las restricciones que impone el tamaño del mercado interno a la diversificación de la actividad industrial. Por ejemplo, la participación del sector agrícola en el PIB es en general más importante en las pequeñas economías, y sus exportaciones son menos diversificadas. Sin embargo, estos indicadores muestran una gran heterogeneidad vinculada en parte a las diferencias de desarrollo. Los países de Centroamérica (excepto Costa Rica) o los países pequeños de América del Sur (excepto Uruguay) presentan rezagos en la formación de su mano de obra, si se les compara con los del Caribe anglohablante. Estos últimos se benefician también de una mejor infraestructura de transporte, energía y telecomunicaciones (aunque sus costos sean altos).
Por último, es en su viabilidad y riesgo que las economías pequeñas se encuentran en general en una situación precaria, vinculada a su mayor vulnerabilidad externa y a una tendencia a presentar mayores déficit comerciales. Sin embargo, ellas no contrarrestan esta vulnerabilidad acumulando reservas internacionales. Por el contrario, el nivel de estas reservas es en general relativamente más bajo que en los demás países. Asimismo, los gobiernos de los países pequeños dependen para sus finanzas públicas del ingreso aduanero y de la ayuda oficial, dos fuentes de ingreso que están en peligro de sufrir una fuerte reducción con el advenimiento del libre comercio y la política de los países industriales de sustituir la ayuda oficial para el desarrollo por un mejor acceso a sus mercados nacionales.

\section{III \\ Orientaciones y perspectivas}

\section{Política económica ${ }^{10}$}

Reiteramos que la vulnerabilidad es una de las características centrales de las pequeñas economías. Reducirla debe ser una prioridad, tanto más cuanto que la integración comercial acompañada de una mayor libertad y de mejores garantías para el movimiento de capitales debería inducir una situación de inestabilidad durante el período de transición. Si la experiencia de las economías latinoamericanas grandes y medianas constituye un indicio, la entrada de capitales puede crear situaciones de recalentamiento de la demanda interna y de sobrevaluación del tipo de cambio que son perjudiciales tanto para la competitividad externa como para la estabilidad del desarrollo, y las expansiones y contracciones sucesivas encierran a la economía nacional en una trampa de débil crecimiento medio.

Resulta indispensable acumular reservas internacionales durante las fases expansivas (esterilizando a la vez el efecto monetario de dicha acumulación) a fin de atenuar la demanda interna durante todo el ciclo económico. Una mayor exposición al riesgo financiero, así como la tendencia a reforzar las normas inter-

\footnotetext{
${ }^{10}$ Esta sección se inspira en particular en las recomendaciones in-
} cluidas en CEPAL (2000). nacionales, exige a su vez una mejor supervisión del sector bancario, tanto por razones económicas como de seguridad pública y de política exterior (en particular en los países que son blanco del tráfico internacional de estupefacientes).

Los países que dependen excesivamente del ingreso aduanero para financiar su gasto público deben iniciar a la brevedad una reforma fiscal, con miras a fortalecer las fuentes internas de contribuciones directas e indirectas y prepararse así para el desmantelamiento de sus barreras aduaneras. Esta reforma, acompañada de una nueva orientación menos procíclica de la política presupuestaria, debería orientarse también a fortalecer el ahorro interno, uno de los puntos débiles de las economías pequeñas.

Es de suma importancia mejorar la calidad del contexto económico e institucional en las pequeñas economías de la región para apoyar su transformación productiva, habida cuenta del peso preponderante que tiene la pequeña empresa en su estructura industrial. Como el impacto de la liberalización comercial sobre la pequeña empresa es cuando menos heterogéneo, hay a la vez oportunidades de creación de actividad y riesgos de quiebras en cadena. Las empresas existentes deberán adaptarse o desaparecer, y sería erróneo querer protegerlas a cualquier precio. No obstante, también es improbable que un grupo importante de peque- 
ñas empresas competitivas surja ex nihilo para aprovechar las nuevas oportunidades que ofrece la apertura de fronteras. Es necesaria una política industrial adaptada para facilitar su surgimiento y para estimular y facilitar las adaptaciones estratégicas en el caso de las empresas existentes.

Esto puede conseguirse por diversas vías, como la modificación y simplificación de las normas administrativas y fiscales; la ayuda a la formación, y los fondos de apoyo a la modernización tecnológica y la exportación. La creación de zonas francas y la promoción de conglomeraciones (clusters) de empresas se adapta especialmente al caso de las pequeñas economías. Aquéllas que tienen que compensar la desventaja de los altos costos de transacción emanados de su aislamiento geográfico (las del Caribe) deben apoyarse forzosamente en sus ventajas naturales a fin de insertarse eficazmente en la economía regional e internacional. La idea es basarse en las exportaciones tradicionales, aumentando a la vez su valor agregado y administrándolas de manera sostenible. Este es en particular el caso del turismo, pero puede ampliarse a la explotación de otros productos naturales (agroalimentarios). La inversión en capital humano y su orientación hacia la creación de ventajas comparativas en ciertos nichos de mercado es también una posibilidad real, como lo demuestra la transición habida en Costa Rica hacia actividades maquiladoras de alta tecnología. La especificidad lingüística de las islas del Caribe anglohablante y su situación geográfica se prestan también a una diversificación potencial en los sectores de servicios basada en el procesamiento de la información (procesamiento de datos, comercio y finanzas). No obstante, debe desplegarse un esfuerzo especial para disminuir en lo posible los costos de transacción (desarrollo de la infraestructura de comunicación, desregulación y control de la competencia).

El decenio que se inicia debería ofrecer nuevas perspectivas a las pequeñas economías para implantar políticas de apoyo al desarrollo productivo. En efecto, las nuevas tendencias tecnológicas permiten liberarse parcialmente de las restricciones impuestas por las economías de escala (generación eléctrica, telecomunicaciones) mientras que el comercio electrónico puede abrir nuevos mercados. No obstante, el nivel de inversión en capital físico y humano que implica la aplicación de estas políticas, así como las exigencias técnicas y normativas del nuevo papel de intermediario y socio que desempeña el Estado en sus relaciones con la economía privada sobrepasan, en general, las capacidades de las pequeñas economías en desarrollo.
En consecuencia, la ayuda oficial al desarrollo sigue siendo más necesaria que nunca para lograr esta inserción en la nueva economía internacional, y debe ponerse un freno a la tendencia actual a reducirla. La ayuda externa se requiere también para paliar los riesgos inherentes a los desastres naturales, fenómenos recurrentes en la región. Además del efecto y los costos directos de los desastres, estos riesgos se traducen en primas de seguro elevadas para las actividades productivas. Para encarar las contingencias, hay que establecer fondos de emergencia, contando con la ayuda internacional; los esfuerzos nacionales deben destinarse a delimitar las zonas de riesgo y establecer una zonificación rigurosa para la explotación de suelos.

\section{Negociaciones comerciales}

Las economías pequeñas tienen más dificultades para representar sus intereses en los foros internacionales. Sus escasos recursos de personal calificado, sea en sus capitales o en Ginebra ante la OMC, se hallan repartidos entre múltiples reuniones comerciales que abordan temas complejos y altamente especializados y que a veces se desarrollan de manera simultánea. Les es sumamente difícil prepararse de manera adecuada para defender sus posiciones, y más aun para tomar la iniciativa.

Cabe recordar que su grado de preparación y capacidad para cumplir los compromisos contraídos a nivel internacional o regional son también bastante bajos, tanto en materia de legislación laboral como protección del medio ambiente o propiedad intelectual. En el contexto específico de las negociaciones de integración regional, la escasa profundidad de las relaciones industriales internas hace que las pequeñas economías tengan más dificultades para respetar los umbrales mínimos de valor agregado de origen regional. Estas normas de origen son tanto más restrictivas cuanto que estos países tienen a veces un comercio importante con otras regiones del mundo (los del Caribe, por ejemplo), lo que puede provocar una desviación importante del comercio cuando se materialice el ALCA.

Por consiguiente, en general se reconoce que las pequeñas economías deberían beneficiarse, al menos durante una fase de transición, de tratos específicos y diferenciados. Estos tratos incluyen, entre otros, un calendario más escalonado a fin de poder adoptar de manera gradual las obligaciones suscritas en el marco de los acuerdos comerciales. La flexibilidad debe abarcar también los umbrales (como los mínimos de valor agregado regional) o las obligaciones legales e 
institucionales. Asimismo, las economías pequeñas tienen que contar con una asistencia técnica considerable, tanto durante como después de las negociaciones. $\mathrm{Si}$ bien estos aspectos son generalmente reconocidos, las negociaciones internacionales han insistido hasta ahora más en la reciprocidad de las obligaciones en el marco de la omc que en la necesaria relación entre comercio y desarrollo, lo que causó de paso el fracaso de una reanudación de las negociaciones en Seattle a fines de 1999. Las negociaciones regionales en curso parecen más propicias, al menos potencialmente.

En la segunda Cumbre de las Américas (18 y 19 de abril de 1998) y últimamente en la Quinta Reunión Ministerial de Comercio (Toronto, 4 de noviembre de 1999), los 34 gobiernos interesados destacaron la necesidad de velar por que se tomaran en consideración las diferencias de nivel de desarrollo y de tamaño económico durante el proceso de negociación del ALCA. No obstante, hasta ahora no se ha dado paso concreto alguno en este sentido y reina la incertidumbre en cuanto a la forma y amplitud que podrían tener tales tratos diferenciados. Esta situación pone de relieve las dificultades de las economías pequeñas para hacer prevalecer sus puntos de vista. Naturalmente que en este contexto sólo la unidad de las pequeñas economías en torno a una posición común puede inclinar la balanza de una manera decisiva. Ahora bien, una alianza de esta especie es difícil de lograr cuando los tres grupos principales de pequeñas economías —el Caribe, Centroamérica y América del Sur- no comparten siempre las mismas ambiciones ni los mismos objetivos estratégicos.

Por cierto que los países de Centroamérica quieren fortalecer sus lazos con México y sobre todo con los Estados Unidos, pero atraviesan por una etapa difícil como grupo de integración, lo que les hace negociar a veces en forma dispersa. Las economías pequeñas de América del Sur se definen en relación con dos polos: el mercado norteamericano, pero también el Mercosur, en especial Brasil. El caso de los países del Caribe es particularmente complejo. Beneficiarios, por el mismo concepto que Centroamérica, de un acceso privilegiado al mercado estadounidense en virtud de la Iniciativa de la Cuenca del Caribe (ICC), estos países - sobre todo Jamaica- han visto en el Tratado de Libre Comercio (TLC) de América del Norte una amenaza de expulsión de ese mercado por los productos de las maquiladoras mexicanas.

A esta inquietud responde la reciente ampliación de las preferencias otorgadas por los Estados Unidos a los productos textiles y de vestuario que —entre otros países beneficiarios de esta medida — exportan los países de la ICC. Sin embargo, estos últimos también son parte de un acuerdo con la Comunidad Europea dentro del marco de la fórmula antigua o nueva de los acuerdos de Lomé, lo que les plantea un problema concreto. ${ }^{11}$ En efecto, en su acepción primitiva, los acuerdos de Lomé representaban un compromiso entre ayuda y comercio que tomaba explícitamente en cuenta la asimetría económica de los asociados: los países ACP en desarrollo, por una parte, y Europa desarrollada, por otra. En particular, reconocían la importancia de ayudar específicamente a los países menos desarrollados, insulares o mediterráneos, para que aprovecharan los beneficios inherentes a estos acuerdos. Numerosos países del Caribe han dependido, y dependen todavía, de esos beneficios para sostener buena parte de su actividad económica, empleo e ingreso. Pero como los acuerdos de este tipo entran en conflicto con los nuevos principios que rigen el comercio internacional, los países ACP suscribieron finalmente en Cotonou un nuevo convenio con la Unión Europea, tras largas negociaciones técnicas que culminaron en febrero de 2000. El nuevo sistema se traducirá en una pérdida potencial para los países ACP que podría ascender al $2 \%$ del valor de sus exportaciones (fuera de protocolos), calculado a partir de los aranceles en vigor en 2000. Para los protocolos relativos a ciertos artículos (plantas, productos agroalimentarios y vestuario) la pérdida de preferencia causada por la aplicación del Sistema General de Preferencias (SGP) sobrepasaría el 10\% (Grupo ACP, 1999).

Para ciertos países ACP de la región, las consecuencias económicas y sociales vinculadas con la reducción progresiva de las subvenciones implícitas en la Convención de Lomé y las amenazas más inmediatas relativas al acceso preferencial de ciertos productos estratégicos (banano) se ven complicadas por nuevas dificultades en el desarrollo de su sector financiero extraterritorial, debido a presiones de los países de la Organización de Cooperación y Desarrollo Económi$\cos$ (OCDE) para reducir los privilegios fiscales otorgados a ese sector. Ahora bien, como lo indica el ejemplo de la maquila, estos países tienen pocas opciones, salvo la concesión de subvenciones directas y sobre todo indirectas — principalmente mediante la exención

\footnotetext{
${ }^{11}$ Cabe señalar que la mayoría de las economías pequeñas de América Latina (Grupo Andino y Centroamérica) se benefician de un régimen preferencial de acceso al mercado europeo, comparable al que se aplica a los países menos adelantados no ACP, como medio de combatir el tráfico de drogas. No obstante, el impacto de este trato ha sido marginal.
} 
fiscal- para atraer la atención de los inversionistas extranjeros y diversificar sus actividades. La estrategia alternativa consistiría en conseguir que la OMC validara la vulnerabilidad económica — que es una constante de las pequeñas economías, en particular insulares- como cláusula de habilitación a fin de extender a las economías vulnerables los privilegios concedidos a los países menos adelantados. Esta opción parece por ahora poco probable.

Cabe recordar que la creación de un comercio demasiado especializado y la asimetría de poder de negociación obran en contra de las economías pequeñas, pero esta desventaja disminuye en función del interés que los países grandes asignan al libre comercio. Por lo tanto, interesa que los pequeños socios comerciales obtengan el apoyo de los grupos de presión en los países importadores (grupos de consumidores, sociedad civil, etcétera) para limitar los riesgos de medidas proteccionistas arbitrarias, a menudo fatales para las pequeñas empresas exportadoras. Asimismo, las instancias regionales de solución de controversias comerciales deben ser lo más transparentes posibles y apoyarse en normas simples, conocidas de antemano, para minimizar los juegos de poder.

(Traducido del francés)
CEPAL (Comisión Económica para América Latina y el Caribe) (1996): El grado de preparación de los países pequeños para participar en el ALCA, México, D.F.

(2000): Equidad, desarrollo y ciudadanía, LC/G.2071, Santiago de Chile.

Dabène, O. (1998): L'intégration régionale dans les Amériques: économie politique de la convergence, Les Etudes du CERI, $\mathrm{N}^{\circ} 45$, París, septiembre.

Damijan J. (1997): Main economic characteristics of small countries: Some empirical evidence, Development and International Cooperation, vol.XIII, $\mathrm{N}^{\circ}$ 24-25, Ljubljana, Yugoslavia, Universidad de Ljubljana, Facultad de ciencias sociales, Centro de relaciones internacionales.

De Sierra, G. (coord.) (1994): Los pequeños países de América Latina en la hora neoliberal, Caracas, Nueva Sociedad.

Escaith, H. y K. Inoue (2001): 'Small economies' tariff and subsidy policies in the face of trade liberalization in the Americas, en CEPAL, XIII Seminario Regional de Política Fiscal. Compendio de documentos, Santiago de Chile.

Escaith, H. y S. Morley (2000): The Impact of Structural Reforms on Growth in Latin America and the Caribbean: An Empirical Estimation, Macroeconomía del desarrollo $N^{\circ} 1$, Santiago de Chile, CEPAL.

Escaith, H. y E. Pérez (1999): Los países pequeños y la integración hemisférica, A. de la Reza y R. Conde (coords.), Nuevas dimensiones de la integración. Del TLCAN al regionalismo hemisférico, México, D.F., Plaza y Valdés Editores.

Finger, J. M., F. Ng y I. Soloaga (1998): Trade policies in the Caribbean countries: A look at the positive agenda, Washington D.C, Grupo del Caribe para la Cooperación en Materia de Desarrollo Económico, junio.

Frankel, J., E. Stein y S. Wei (1995): Trading blocs and the Americas: The natural, the unnatural and the supernatural, Journal of Development Economics, vol. 47, № 1, Amsterdam, Países Bajos, Elsevier Science Publishers, B.V.

Grupo ACP (1999): Conséquences pour les Pays ACP de l'application du système de préférence généralisées, Documento de trabajo, Bruselas, 20 de abril.

Gutiérrez, M. A. (1996): Is small beautiful for the economic integration: The Americas, Journal of World Trade, vol. 30, $\mathrm{N}^{\circ}$ 4, Ginebra, Werner Publishing Company Ltd., agosto.

Hufbauer, G. y J. Schott (1994): Western Hemisphere Economic Integration, Washington D. C., Institute for International Economics (IIE).

McLaren, J. (1997): Size, sunk costs and Judge Bowker's objection to free trade, The American Economic Review, vol. 87, $\mathrm{N}^{\circ} 3$, Nashville, Tennessee, American Economic Association.

Park, J. (2000): International trade agreements between countries of asymmetric size, Journal of International Economics, vol.50, Amsterdam, Países Bajos, North-Holland Publishing Company.

Real de Azúa, C. (1977): Las pequeñas naciones y el estilo de desarrollo 'constrictivo', Revista de la CEPAL, $\mathrm{N}^{\circ}$ 4, S77.II.G.5, Santiago de Chile, CEPAL, segundo semestre.

Rodriguez, F. y D. Rodrik (1999): Trade Policy and Economic Growth: A Skeptic's Guide to the Cross-National Evidence, Cambridge, Massachusetts, Harvard University, enero.

Ros, J. (2000): Development Theory and the Economics of Growth, Ann Arbor, Michigan University Press.

Salvatore, D. (1997): The economic performance of small versus large nations, Development and International Cooperation, vol. XIII, N 24-25, Ljubljana, Yugoslavia, Universidad de Ljubljana, Facultad de ciencias sociales, Centro de relaciones internacionales.

Stallings, B. y W. Peres (2000): Growth, Employment and Equity: The Impact of the Economic Reforms in Latin America and the Caribbean, Washington, D.C., The Brookings Institution. 